\title{
Do Investors Understand Really Dirty Surplus?
}

\author{
Wayne R. Landsman, ${ }^{1}$ Bruce L. Miller, ${ }^{2}$ Ken Peasnell, ${ }^{3}$ and Shu Yeh ${ }^{4}$
}

July 2010

1. Kenan-Flagler Business School, University of North Carolina at Chapel Hill, Chapel Hill, NC 27599, wayne_landsman@unc.edu.

2. Anderson School of Management, University of California, Los Angeles, Los Angeles, CA 90095, bruce.miller@anderson.ucla.edu.

3. Management School, Lancaster University, Lancaster, LA1 4YX, UK, k.peasnell@lancaster.ac.uk.

4. College of Management, National Taiwan University, Taipei, Taiwan, ROC, shuyeh@ntu.edu.tw.

\footnotetext{
We thank workshop participants at the 2009 European Accounting Association Congress, the 2008 UNC-Duke Fall Camp, the 2008 Yale Fall Camp, the Chinese University of Hong Kong, National Taiwan University, National University of Singapore, the Norwegian School of Economics, UCLA, the University of Graz, and the Vienna University of Economics and Business Administration, Frøystein Gjesdal, and two anonymous reviewers for helpful comments. We acknowledge funding from the Center for Finance and Accounting Research at UNC-Chapel Hill and Republic of China National Science Council (NSC 96-2416-H-002-038; NSC97-2410-H-002-042).

Corresponding author: Wayne Landsman, Kenan-Flagler Business School, University of North Carolina, Chapel Hill, NC 27599-3490, 919-962-3221, wayne_landsman@unc.edu.
} 


\section{Do Investors Understand Really Dirty Surplus?}

ABSTRACT: This study addresses whether firms' share prices correctly reflect two accounting measures, dirty surplus and really dirty surplus. Dirty surplus is readily observable from the financial statements, but really dirty surplus, which arises from recognizing equity transactions such as employee stock option exercises at other than fair market value, is not. Findings show that dirty surplus and really dirty surplus are irrelevant for forecasting abnormal comprehensive income. However, findings also indicate that investors appear to undervalue really dirty surplus. Hedge returns are insignificant when portfolios are formed based on dirty surplus, but are significantly positive based on really dirty surplus. Really dirty surplus positive hedge returns are robust to a variety of sensitivity tests. Taken together, the findings are consistent with either investors overvaluing firms that have large negative really dirty surplus or really dirty surplus being correlated with an unmodeled risk factor.

Keywords: Dirty surplus accounting; Equity valuation; Hedge returns.

Data Availability: Data are available from sources identified in the paper. 


\section{Do Investors Understand Really Dirty Surplus?}

\section{INTRODUCTION}

A substantial and growing literature considers whether investors properly assess the characteristics of earnings and its components when setting stock prices. The question we address is whether firms' share prices correctly reflect two accounting measures that have received relatively little attention to date. The first of these is commonly referred to as "dirty surplus," which is a component of comprehensive income that is excluded from reported earnings, and therefore violates clean surplus accounting. We label the second accounting measure we consider "really dirty surplus," which arises when a firm issues or reacquires its own shares in a transaction that does not record the shares at fair market value. Examples of this kind of transaction are shares issued in a stock option exercise and a conversion of a bond into common stock. Prior to the implementation of FASB Statement No. 141, the pooling of interest method of accounting for business combinations could also result in substantial really dirty surplus. If investors fully understand the predictive value of these accounting amounts, then it should not be possible to develop a profitable trading strategy based on the magnitudes of these items.

Unlike dirty surplus, which is readily observable from the financial statements, really dirty surplus is unobservable. That is, even the most sophisticated investor cannot estimate readily the valuation impact of equity transactions that give rise to really dirty surplus 
because equity transactions are recognized in the financial statements using an accounting-based rather than a market-based measure of the value of equity. The estimation task investors face is exacerbated by the fact that a firm can engage in numerous such transactions throughout the year. As a result, really dirty surplus transactions are less likely to be correctly priced than are dirty surplus transactions.

Using financial statement and stock price data from 1976-2006, we first assess whether investors properly value each of these two components of earnings by estimating a residual income forecasting equation and an attendant valuation equation that includes both of these components. If current residual income is sufficient for forecasting next period's residual income and current residual income and equity book value are sufficient for valuing current equity, then the forecasting and valuation coefficients on the income components of interest will be linked in a predictable manner. Finding a mismatch between the components' forecasting and valuation equation coefficients would be consistent with investors mispricing of the components.

We also conduct hedge portfolio returns tests. We adopt a buy-and-hold strategy to go long in firms with relatively large dirty or really dirty surplus and to short firms with relatively small dirty or really dirty surplus. We conjecture that small firms' prices are less likely to reflect fully all publicly available information because investors incur proportionately greater transaction costs; as a result, they are less closely followed and less 
likely to be subject to detailed accounting analysis. We therefore conduct both sets of tests separately for small, medium, and large firms to assess whether pricing effects are related to firm size.

We find that both dirty surplus and really dirty surplus are irrelevant for forecasting abnormal very comprehensive income for all three firm size groups. Taking these results at face value, if investors correctly understand the implications of these persistence findings for valuation, then each kind of dirty surplus should be irrelevant for valuation for all firms. This prediction is borne out in the case of dirty surplus. However, the findings indicate that investors appear to undervalue really dirty surplus, which is consistent with investors being unable to assess the economic implications of really dirty surplus transactions.

Buy-and-hold hedge return results support the findings from the tests linking the forecasting and valuation equations. As expected, hedge returns are insignificantly different from zero when based upon dirty surplus, regardless of firm size and investing horizon. In contrast, the hedge returns based on really dirty surplus are significantly positive for all three firm size groups. We also consider an alternative to our buy-and-hold procedure for computing hedge returns. Findings based on mean returns for monthly calendar-time hedge portfolios indicate that significantly positive hedge returns are concentrated within small firms. Findings from additional tests reveal that inferences relating to hedge returns are 
insensitive to including controls for four previously identified mispricing anomalies, and to sampling procedures designed to attempt to focus on sources of really dirty surplus.

Taken together, the findings are consistent with investors overvaluing firms which have large negative really dirty surplus. However, several cautionary notes are in order. First, although the hedge returns findings are consistent with mispricing of really dirty surplus, the possibility remains that the mismatch of the really dirty surplus forecasting and valuation coefficients is the result of model misspecification rather than mispricing. Second, as is likely the case with investors, we are unable to trace the sources of really dirty surplus to particular types of equity transactions. As a result, we cannot determine the extent to which potential mispricing arises from each type of transaction, i.e., our findings can only be interpreted as reflecting the aggregate effect of the various types of transactions. However, even if we could trace the sources of really dirty surplus, any resulting hedge returns might still be attributable to an unmodeled risk factor.

Our study adds to prior research finding evidence of investors' apparent failure to link the forecasting attributes of accounting amounts with the pricing implications (e.g., Bernard and Thomas 1989; Sloan 1996; Barth et al. 1999; Bradshaw and Sloan 2002; Burgstahler et al. 2002; Brown and Sivakumar 2003; Doyle et al. 2003; and Landsman et al. 2007). Our findings support prior studies that find that investors understand the forecasting properties and valuation implications of dirty surplus (Dhaliwal et al. 1999; O'Hanlon and Pope 1999; 
Biddle and Choi 2006; Chambers et al. 2007). Although Landsman et al. (2006) examine valuation implications of expected future equity transactions arising from the exercise of employee stock options, their study does not address whether investors take full account of the valuation implications of past option exercises. Core et al. (2002) report findings suggesting that dilutive transactions, including those arising from employee stock option grants, are poorly dealt with in reported diluted earnings per share, leaving open the possibility that investors may have difficulty in valuing such transactions.

Section II provides the motivation for the study and explains how dirty surplus and really dirty surplus are defined. Section III presents the research design, including computation of dirty surplus and really dirty surplus, development of the forecasting and valuation equations, and description of our hedge return strategy. Section IV describes the sample and data, and Section V presents the findings. Section VI summarizes and concludes.

\section{MOTIVATION}

The empirical issue that is central to this research is whether firms' share prices correctly reflect two accounting measures that have received relatively little attention to date.

The first of these is commonly referred to as dirty surplus, $D S$, which is a component of comprehensive income that is excluded from reported earnings, and therefore violates clean surplus accounting (Ohlson 1995; Feltham and Ohlson 1995). Dirty surplus accounting results in the basic residual income valuation model yielding an inaccurate estimate of equity 
value because the sum of current book value and future net incomes does not equal the sum of future net dividends.

The second accounting measure we consider we label really dirty surplus, RDS, which arises when a firm issues or reacquires its own shares in a transaction that does not record the shares at fair market value. The primary sources of $R D S$ include employee stock option exercises, conversion of preferred stock and bonds, and mergers accounted for as pooling of interests. Whereas equity issued under employee stock option exercises or convertible instruments can give rise to unrecorded expenses, equity issued under pooling of interests gives rise to an unrecorded asset. ${ }^{1}$

RDS violates the super clean surplus concept (Feltham 1996; Christensen and Feltham 2003), under which it is assumed that net dividends or share issuances are recorded at fair market value. When this condition is violated, the discounted present value of future net dividends (or equivalently, the sum of equity book value and discounted present value of future abnormal earnings) will not equal the market value of equity relating to current shares outstanding, but rather will equal the market value of equity relating to current shares outstanding plus the market value of other equity claimants. Because the equity transactions

\footnotetext{
${ }^{1}$ Equity issued under the pooling-of-interests method is not recognized at fair market value. In contrast, if purchase accounting were applied instead of the pooling-of-interest method, $R D S$ would not arise; instead, the amount of $R D S$ attributed to pooling of interests would be recognized in the financial statements as goodwill.
} 
that give rise to $R D S$ generally are recorded in the financial statements at less than market value, $R D S$ is generally negative. ${ }^{2}$

$D S$ is readily observable from the financial statements. When one takes a clean surplus accounting perspective, as comprehensive income does, dirty surplus becomes a component of earnings. Dirty surplus is conventionally defined as the sum of recognized revenue or expense items that bypass the income statement. Unlike $D S, R D S$ is not reported in the financial statements. A super-clean surplus accounting perspective requires that both dirty surplus and really dirty surplus become components of earnings so that the discounted stream of future residual income and current equity book sums to the market value of equity of current shareholders. If investors fully understand the implications of $D S$ and $R D S$ for valuation, then it should not be possible to develop a profitable trading strategy based on the magnitudes of these items.

To see these points more clearly, consider first the following version of clean-surplus:

$$
B V E_{t}=B V E_{t-1}+X_{t}+D S_{t}-D i v_{t}+P_{t}^{A}\left(N_{t}-N_{t-1}\right)
$$

where $B V E_{t}$ is defined as ending equity book value, $X_{t}$ represents net income, $D S_{t}$ is dirty surplus, $D i v_{t}$ is dividends, $N_{t}$ is the number of shares outstanding at the end of period $t$, and $P_{t}^{A}$ is the price per share used to record the issuance or reacquisition of equity

\footnotetext{
${ }^{2}$ It is possible that $R D S$ could be positive. For example, consider a bond with a book value of $\$ 175$ and fair value of $\$ 125$ that is converted in to equity whose fair value is $\$ 150$. In this case, $R D S$ would be a positive amount equal to $\$ 25$. Likewise, unrecorded goodwill associated with a merger accounted for under pooling of interests could give rise to negative unrecorded goodwill, and hence positive RDS.
} 
shares in the accounting system. Note that if $D S_{t}$ is zero, then the accounting is said to satisfy clean surplus accounting.

Let $P_{t}^{M}$ be the market price per share at the date of issuance or reacquisition of equity shares. We define really dirty surplus, $R D S_{t}$, by

$$
R D S_{t} \equiv\left(N_{t}-N_{t-1}\right)\left(P_{t}^{A}-P_{t}^{M}\right)
$$

By combining (1) and (2), we arrive at:

$$
D S_{t}+R D S_{t}=B V E_{t}-B V E_{t-1}-X_{t}+D i v_{t}-P_{t}^{M}\left(N_{t}-N_{t-1}\right)
$$

$D S_{t}, B V E_{t}, B V E_{t-1}, X_{t}$, and $D i v_{t}$ are readily observable in the financial statements. The

final term on the right hand side of (3), $P_{t}^{M}\left(N_{t}-N_{t-1}\right)$ is not reported in the financial statements and therefore needs to be estimated.

Note that if both $D S_{t}$ and $R D S_{t}$ are zero in (3), then the accounting is said to satisfy super-clean surplus accounting. The next section allows for both nonzero $D S_{t}$ and $R D S_{t}$ and super-clean surplus accounting by setting $V C N I_{t}=X_{t}+D S_{t}+R D S_{t}$, where $V C N I$ is "very comprehensive" net income. Our definition of $R D S$, and hence VCNI, attributes all of the violation of super-clean surplus accounting to the period during which the equity transaction is recorded at a price other than fair market value. Christensen and Feltham (2003) show that when super-clean surplus accounting holds in periods subsequent to time $t$, application of the residual income valuation model will yield an estimate of equity value that equals the market value of equity of existing shares. Whether super-clean surplus accounting 
holds up to and including period $t$ simply affects the opening balance of equity book value at time $t$. However, if $P^{M}$ and $P^{A}$ differ for transactions in periods subsequent to time $t$, then super-clean surplus accounting will be violated and hence the residual income model will not yield an estimate of equity value that equals the market value of existing shares. ${ }^{3}$

As stated above, the empirical issue that is central to this research is whether firms' price per share correctly reflects $D S$ and $R D S$. If it does, then one should not be able to develop a trading strategy based on $D S$ or $R D S$ that generates future abnormal returns. There are several reasons why we expect that $R D S$ is the better earnings component on which to base a trading strategy. First, as noted above, unlike $D S, R D S$ is not reported in the financial statements. Second, $R D S$ appears to be inherently complex. For example, for most earnings components, any "overstatement" or "understatement" reverses in future periods; this does not hold for RDS. Third, research on DS (Dhaliwal et al. 1999; O'Hanlon and Pope 1999; Biddle and Choi 2006; Chambers et al. 2007) is not especially encouraging about the possibility that it can be used to construct a profitable trading strategy.

Nonetheless, there are at least two compelling reasons for conducting our tests for $D S$ as well as $R D S$. First, our study is the first to examine whether investors properly price $D S$

\footnotetext{
${ }^{3}$ Landsman et al. (2006) show that, in the case of employee stock options (i.e., contingent equity), when only clean surplus holds, the estimate of equity value equals the sum of the market value of existing shares and employee stock options. The study's model considers the case in which employee stock options are granted at time $t$ or earlier. The residual income valuation model does not yield a estimate of the value of existing shares because the options are not yet exercised, and when they are exercised in the future, the new shares will be recognized at $P^{A}$ rather than $P^{M}$.
} 
based on the forecasting and valuation equations in the Ohlson (1999) model as well as on

hedge return tests. Second, because we do not necessarily expect to find evidence of

mispricing relating to $D S$, finding this is the case mitigates concerns that finding evidence of

mispricing relating to $R D S$ is attributable to misspecification of our empirical procedures.

\section{RESEARCH DESIGN}

\section{Computation of $D S$ and $R D S$}

Following Dhaliwal et al. (1999) and Chambers et al. (2007), we compute DS as the sum of (a) the change in the balance of unrealized gains or losses on marketable securities (change in Compustat \# 238), (b) the change in the cumulative foreign exchange adjustment (change in Compustat \# 230), and (c) 0.65 times the change in additional pension liability in excess of unrecognized prior service costs (change in Min [(Compustat \# 297 - \# 298), 0]).

Based on (3), we compute $R D S$ as the change in the book value of common equity (Compustat \#60 + \#227 - \#242), less DS, less net income (Compustat \# 172 - \#19), plus dividends (Compustat \# 21), less share price at middle of fiscal year times change in common shares outstanding (Compustat \# 25, adjusted for stock dividends and splits). ${ }^{4}$ Note that because we (and investors) cannot readily compute using the individual underlying equity

\footnotetext{
${ }^{4}$ To the extent that our definition of $D S$ does not include all dirty surplus items (e.g., the cumulative effects on equity of retrospective accounting changes), $D S$ will be measured with error. Because $R D S$ is net of $D S$, such items will appear as part of our measure of $R D S$. Also, our measure of $R D S$ includes treasury stock transactions taking place at prices that differ from the market price at the middle of the fiscal year.
} 
transactions, $R D S$ likely measures the true underlying construct with error. ${ }^{5}$ Share prices are from the CRSP database.

\section{Forecasting and Valuation Equations}

To examine how the dirty surplus and really dirty surplus components of income

relate to equity value, we adopt the abnormal earnings and equity valuation equations from

Barth et al. (1999), which are based on the linear information system developed in Ohlson (1999):

$$
\begin{aligned}
& V C N I_{i t+1}^{a}=\omega_{0}+\omega_{1} V C N I_{i t}^{a}+\omega_{2} D S_{i t}+\omega_{3} R D S_{i t}+\omega_{4} B V E_{i t}+\varepsilon_{i t+1} \\
& M V E_{i t}=\alpha_{0}+\alpha_{1} V C N I_{i t}^{a}+\alpha_{2} D S_{i t}+\alpha_{3} R D S_{i t}+\alpha_{4} B V E_{i t}+u_{i t+1}
\end{aligned}
$$

(4) is the abnormal earnings forecasting equation, where abnormal very comprehensive earnings, $V C N I_{t}^{a}$, is defined as very comprehensive earnings, $V C N I_{t}$, less a normal return on beginning equity book value, $B V E_{t-1}$, i.e., $V C N I_{t}-r B V E_{t-1}$. Very comprehensive income is net income, $N I_{t}$, plus both dirty surplus and really dirty surplus. Following Ohlson (1999) and Barth et al. (1999), $V C N I_{t}$ is partitioned into $N I_{t}, D S_{t}$, and $R D S_{t}$. The linear information system represented by (4) and (5) implicitly assumes that current earnings amounts are predictive of all future earnings. To the extent that this assumption is violated, the algebraic links between forecasting coefficients in (4) and the valuation coefficients in (5) described below do not necessarily hold. Of particular significance to this study is whether current realizations of $D S$ and $R D S$ are predictive of future $V C N I^{a}$ that includes future

\footnotetext{
${ }^{5}$ In particular, the use of mid-year prices in the construction of $R D S$ is arbitrary. We test the sensitivity of our findings to measuring $R D S$ at alternative dates using both end-of-year and average of beginning- and end-of-year prices. Untabulated findings based on these alternative measures reveal that none of the inferences is affected.
} 
realizations of these variables.

In (4), $\omega_{1}$ reflects the persistence of abnormal very comprehensive earnings. Prior research (e.g., Dechow et al. 1999; Barth et al. 1999, 2005) leads us to predict that $\omega_{1}$ is positive. ${ }^{6}$ The coefficients on the $D S$ and $R D S$ earnings components, $\omega_{2}$ and $\omega_{3}$, reflect the incremental effects on the forecast of abnormal earnings of knowing these components. If all earnings components have the same ability to forecast $V C N I_{t+1}^{a}, \omega_{2}$ and $\omega_{3}$ will both equal zero, and thus knowing each component of earnings does not aid in forecasting abnormal earnings. As a result, we test the null hypotheses that $\omega_{2}=0$ and $\omega_{3}=0$ against the alternative that $\omega_{2} \neq 0$ and $\omega_{3} \neq 0$.

Following Ohlson $(1999,150)$, we define $D S(R D S)$ as being "forecasting irrelevant" if the quadruple $\left\{N I_{t}, R D S_{t}, B V E_{t}, B V E_{t-1}\right\} \quad\left(\left\{N I_{t}, D S_{t}, B V E_{t}, B V E_{t-1}\right\}\right)$ contains the same information as the quintuple $\left\{N I_{t}, D S_{t}, R D S_{t}, B V E_{t}, B V E_{t-1}\right\}$ for purposes of forecasting $V C N I_{t+1}^{a}$. Because $D S$ and $R D S$ are components of $V C N I_{t}^{a}$, the total coefficients on $D S_{t}$ and $R D S_{t}$ are $\omega_{1}+\omega_{2}$ and $\omega_{1}+\omega_{3} . \omega_{4}$ is not included in the total coefficient on either $D S_{t}$ or $R D S_{t}$ because $B V E_{t}$ is unchanged across the different definitions of clean surplus and is therefore invariant to the definition of clean surplus. Thus, if $\omega_{1}+\omega_{2}=0\left(\omega_{1}+\omega_{3}=0\right), D S$ $(R D S)$ is irrelevant for forecasting abnormal earnings. Conversely, if $\omega_{1}+\omega_{2} \neq 0\left(\omega_{1}+\omega_{3} \neq\right.$ $0)$, then $D S(R D S)$ is said to have abnormal earnings "forecasting relevance." To examine whether dirty surplus and really dirty surplus components of comprehensive income are forecasting irrelevant, we test the null hypotheses that $\omega_{1}+\omega_{2}=0$ and $\omega_{1}+\omega_{3}=0$ against

\footnotetext{
6 Ohlson $(1995,1999)$ permits the forecasting and valuation equations to include "other information."

Fairfield et al. (2003) shows that accruals and asset growth have incremental ability to predict future return on assets. Accordingly, viewing accruals and asset growth as "other information," below we report findings from alternative specifications of (4) and (5) that include proxies for these variables as additional explanatory variables.
} 
the alternatives that $\omega_{1}+\omega_{2} \neq 0$ and $\omega_{1}+\omega_{3} \neq 0$. Note that $\omega_{1}$ reflects the forecasting relevance of the $V C N I_{t}^{a}-D S_{t}-R D S_{t}=N I_{t}-r B V E_{t-1}$ component of $V C N I_{t}^{a}$.

Equation (5) is the valuation equation based on the information dynamics in (4). $\alpha_{2}$

and $\alpha_{3}$, the valuation multiples on $D S$ and $R D S$, can be interpreted in a symmetrical fashion.

This follows from the fact that although $D S_{t}$ is by definition included in $B V E_{t}$, it follows from (1) and (3) that $R D S_{t}$ that arises from dilutive transactions is normally included in $B V E_{t}$ as well. ${ }^{7}$ Analogous to the interpretation of $\omega_{2}\left(\omega_{3}\right)$ in (4), $a_{2}\left(\alpha_{3}\right)$ reflects the incremental effect on valuation from knowing $D S(R D S)$. If all earnings components are equally persistent then they should have the same relation with equity value. If this is the case, then $a_{2}$ and $a_{3}$ will equal zero, and knowing each component of earnings will not aid in explaining equity value. Thus, we test the null hypothesis that $a_{2}=0\left(a_{3}=0\right)$ against the alternative that $a_{2} \neq 0\left(a_{3} \neq 0\right)$. We define $D S(R D S)$ as being "valuation irrelevant" if the quadruple $\left\{N I_{t}, R D S_{t}, B V E_{t}, B V E_{t-1}\right\} \quad\left(\left\{N I_{t}, D S_{t}, B V E_{t}, B V E_{t-1}\right\}\right)$ contains the same information as the quintuple $\left\{N I_{t}, D S_{t}, R D S_{t}, B V E_{t}, B V E_{t-1}\right\}$ for purposes of valuation.

\footnotetext{
7 This can be illustrated by the following simple bond conversion example. Consider a firm that has a convertible bond outstanding on its books at $\$ 100$ that is converted into shares worth $\$ 150$ at time $t$. Under current GAAP, the share issuance will be recorded at $\$ 100$. If we assume for simplicity that $X_{t}=D S_{t}=0$ and that $B V E_{t-1}=\$ 1,000$, it follows that $B V E_{t}=1,000+100=\$ 1,100$. If this transaction were to be accounted for on a super-clean surplus basis, the share issuance would be recorded at $\$ 150$, with the resultant cost of conversion appearing as $R D S_{t}=-50$. We can deduce from (3) that under super-clean surplus accounting $B V E_{t}=1,000-50$ $+150=\$ 1,100$ as well. Although the calculations are more complex in the case of employee stock options, the same conclusions apply. Note that in the case of mergers accounted for under pooling-of-interests, the inclusion of $R D S$ in $B V E_{t}$ would leave $B V E_{t}$ unchanged only if the asset (goodwill) associated with an acquisition were immediately expensed.
} 
Also analogous to (4), the total valuation coefficient on $D S(R D S)$ equals $a_{1}+a_{2}\left(a_{1}+a_{3}\right)$.

Thus, if $\alpha_{1}+\alpha_{2}=0 \quad\left(\alpha_{1}+\alpha_{3}=0\right), D S(R D S)$ is irrelevant for valuation. ${ }^{8}$ Conversely, if $a_{1}$ $+a_{2} \neq 0\left(a_{1}+a_{3} \neq 0\right)$, then $D S(R D S)$ is "valuation relevant." Analogous to the interpretation of $\omega_{1}$ in (4), $a_{1}$ reflects the value relevance of the $V C N I_{t}^{a}-D S_{t}-R D S_{t}=N I_{t}-r B V E_{t-1}$ component of $\mathrm{VCNI}_{t}^{a}$.

Barth et al. (1999) derives a formula linking the coefficients in (4) and the two suppressed equations with the coefficients in (5). For our purposes, we are not interested in exact coefficient magnitudes based on imposing a full set of linear information dynamics.

Instead, we are interested in the weaker prediction that the sign of $a_{1}+a_{2}\left(a_{1}+a_{3}\right)$ will be based on the sign of $\omega_{1}+\omega_{2}\left(\omega_{1}+\omega_{3}\right)$.

If prices are determined rationally, then if $D S$ or $R D S$ is irrelevant for forecasting the next period amount, each should be valuation irrelevant as well if the linear dynamics in (4) and (5) hold. Also, the sign of $a_{1}+a_{2}\left(a_{1}+a_{3}\right)$ will be the same as the sign of $\omega_{1}+\omega_{2}$ $\left(\omega_{1}+\omega_{3}\right)$. If we find apparent evidence of mispricing based on the empirical coefficients from estimating (4) and (5), then a buy-and-hold strategy of going long in relatively underpriced stocks and short in relatively overpriced stocks should yield excess returns.

\footnotetext{
${ }^{8}$ Note that under the Ohlson (1999) framework, value irrelevance (e.g., which occurs for $D S(R D S)$ when $\left.\alpha_{1}+\alpha_{2}=0 \quad\left(\alpha_{1}+\alpha_{3}=0\right)\right)$ of an earnings component implies that it has no impact on goodwill, which is the difference between equity market value and book value. Ohlson $(1999,152)$ further states: "an incremental dollar of transitory earnings adds a dollar to market value." This claim is easy to validate as long as one keeps in mind that a dollar of transitory earnings also adds a dollar to book value."
} 
Any mismatch between the forecasting and valuation results for $D S$ or $R D S$ need not necessarily be attributable to its mispricing by investors. It might be the case, for example, that although $R D S_{t}$ cannot be used to forecast $V C N I_{t+1}^{a}$, it could be used to forecast $V C N I_{t+k}^{a}(k=2,3, \ldots)$. If this were the case, $R D S$ would not be valuation irrelevant, and the mismatch between forecasting and valuation coefficients would be attributable to variables omitted from both equations. The hedge returns tests provide a means of examining this issue.

If transaction cost considerations imply that small firms are more difficult to price, then we would expect the hedge portfolio returns to be greater than in the case of larger firms. Therefore, we estimate and test predictions relating to (4) and (5) separately for small, medium, and large firms based on equity market value and conduct hedge return tests also separately for small, medium, and large firms.

\section{Hedge Portfolio Strategy and Procedure}

\section{Hedge Strategy Overview}

We determine the hedge portfolio strategy in the following manner. First, for each sample year, we rank firms according to either $D S$ or $R D S$ as a fraction of end-of-year equity book value, $B V E .^{9}$ We then form ten portfolios whereby the first (tenth) portfolio contains those observations with the smallest (largest) fraction of $D S$ or $R D S$. Second, within each of

\footnotetext{
${ }^{9}$ Untabulated findings based on $D S$ and $R D S$ deflated by total assets result in no changes in inferences.
} 
the ten $D S$ or $R D S$ portfolios we rank firms according to equity market capitalization and assign each firm to one of three equal-sized groups of firms comprising the small, medium, and large firms. This procedure results in there being ten portfolios within each of the three firm size groups. It also ensures that the magnitude of $D S$ or $R D S$ does not vary systematically across the three firm size groups, and thereby helps to mitigate the confounding effect of firm size when conducting our hedge portfolio tests. ${ }^{10}$ Third, we then combine observations from all sample years, retaining the firm size designation and $D S$ and $R D S$ portfolio rankings. This results in there being three firm-size groups, within each of which there are ten $D S$ or $R D S$ portfolios. ${ }^{11}$ Fourth, within each of the three firm size groups, for each firm in the ten $D S$ or $R D S$ portfolios, we compute the risk-adjusted return over all sample years. Fifth, we compute the hedge return by deducting the equally-weighted mean risk-adjusted return on the portfolio(s) comprising firms we expect to be most overvalued from the return on portfolio(s) comprising firms we expect to be either undervalued or least

${ }^{10}$ By design, this procedure is a double-conditional sort of first $\operatorname{RDS}$ (or $D S$ ) then size. As a consequence, this procedure can fail to adequately control for size differences between long and short RDS portfolios. To assess the sensitivity of hedge returns, we reversed the sorting procedure and recomputed hedge returns sorting firm-years using a double-conditional sort of first size then $R D S$. Hedge return findings based on this alternative procedure result in inferences that are substantially the same as those based on the tabulated hedge return findings.

11 Because firm size is increasing during our sample period, some large firms in early sample years would be considered small firms in later sample years. However, because firm size groupings are determined annually, our procedure mitigates year effects on our hedge portfolio test inferences. 
overvalued. $^{12}$

We predict that overvaluation is most likely to occur for firms whose income is overstated relative to very comprehensive net income, and where the market fails to understand the economic implications of such overstatement. As noted in Section II, we expect these conditions to be more descriptive for $R D S$ than $D S$. Recall that $R D S$ is generally non-positive because the accounting procedures that give rise to $R D S$ arise from equity transactions that generally are recorded at less than market value. Our hedge strategy is therefore long in firms with least negative $R D S$ and short in firms with most negative $R D S$. We employ a similar strategy for $D S$, i.e., go long in firms with most positive $D S$ and short in firms with most negative $D S$. As noted above, we do not expect this $D S$-based hedge strategy to yield significant positive (or negative) excess returns.

Following Bernard and Thomas (1990), we compute the hedge return for each of the three firm size groups by going long (short) in the firms in the top three (bottom three) $D S$ or $R D S$ portfolios. Combining observations in the top three and bottom three $D S$ or $R D S$ portfolios confers the benefit of mitigating the potential effects of measurement error in the extreme $D S$ or $R D S$ portfolios. We employ the hedge portfolio tests to complement the tests based on the forecasting and valuation equations. In particular, if the forecasting and

\footnotetext{
12 Untabulated findings based on hedge returns computed with value-weighted portfolio risk-adjusted returns result in no change in inferences. Additional untabulated findings based on cumulative abnormal returns also result in no change in inferences.
} 
valuation equations yield evidence of mispricing, notably undervaluation of $D S$ or $R D S$, then the hedge portfolio tests should yield evidence that excess returns can be earned by exploiting such undervaluation. Conversely, if the forecasting and valuation equations yield no evidence of mispricing, then the hedge portfolio tests should yield evidence that excess returns cannot be earned following our hedge strategy.

\section{Hedge Strategy Implementation Details}

To estimate risk-adjusted return, we need a measure of expected stock return.

Following Ang and Liu (2004), Ibbotson Associates (2005), Massa et al. (2005), and Barth et al. (2008), we use the Fama and French (1993) three-factor model, supplemented with the momentum factor (Jegadeesh and Titman 1993; Carhart 1997), with time-varying factor loadings, risk-free rates, and risk premia. We calculate each firm's expected equity return for month $t+1$ as of month $t, E R_{i, t+1}$, conditional on the expected factor returns in month $t+1$, based on (6):

$$
\begin{aligned}
E R_{i, t+1}= & R_{f, t+1}+\beta_{R M R F, i, t+1}\left(R_{M, t+1}-R_{f, t+1}\right)+\beta_{S M B, i, t+1} S M B_{t+1} \\
& +\beta_{H M L, i, t+1} H M L_{t+1}+\beta_{M O M, i, t+1} M O M_{t+1},
\end{aligned}
$$

where $\beta_{R M R F, i, t+1}, \quad \beta_{S M B, i, t+1}, \quad \beta_{H M L, i, t+1}$, and $\beta_{M O M, i, t+1}$ are firm-specific coefficients estimated from (7) below. $R_{M, t+1}-R_{f, t+1}, S M B_{t+1}, H M L_{t+1}$, and $M O M_{t+1}$ are the expected monthly Fama-French and momentum factor returns for month $t+1$. We estimate the expected monthly factor returns for month $t$ by first calculating each factor's average monthly return over the 60 months prior to month $t$. The difference, $R_{M, t}-R_{f, t}$, is the monthly return of 
the market portfolio in excess of the risk-free rate, $H M L_{t}$ and $S M B_{t}$ are the monthly returns to the book-to-market and size factor-mimicking portfolios, respectively, as described in Fama and French (1993), and $M O M_{t}$ is the monthly return to the momentum factor-mimicking portfolio. The risk-adjusted return for firm $i$ in month $t+1$ is the difference between the firm's realized return in month $t+1, R_{i, t+1}$, and its expected return, $E R_{i, t+1}$. We then use these monthly risk-adjusted returns to compute annual returns. In the hedge return tests, we cumulate return three months after fiscal year end to ensure that the financial statements are available to the public.

For each firm, we estimate the betas associated with the firm's return to each of the Fama-French and momentum factors by estimating the following monthly time-series regression:

$$
R_{i, t}-R_{f, t}=\alpha_{i}+\beta_{R M R F, i}\left(R_{M, t}-R_{f, t}\right)+\beta_{S M B, i} S M B_{t}+\beta_{H M L, i} H M L_{t}+\beta_{M O M, i} M O M_{t}+\varepsilon_{i, t},
$$

where $R_{i, t}-R_{f, t}$ is the firm's monthly return in excess of the risk-free rate. We estimate (7) using the most recent 60 month returns prior to the month $t$. This results in estimated coefficients, $\hat{\beta}_{R M T F, i, t}, \hat{\beta}_{S M B, i, t}, \hat{\beta}_{H M L, i, t}$, and $\hat{\beta}_{M O M, i, t}$, which are updated monthly. We define our forecast of each factor beta for month $t+1$ using the fitted value for that factor for month $t$, e.g., $\quad \beta_{R M T F, i, t+1}=\hat{\beta}_{R M T F, i, t}$.

Following Doyle et al. (2003), we compute hedge returns over one-, two-, and three-year horizons. We conjecture that if hedge returns continue to increase over longer horizons, then 
such evidence would be indicative of unmodeled risk differences. Therefore, we expect hedge returns to flatten over the three year horizon. To avoid imposing the assumption of normality of the distribution of excess returns, we report an additional test for significance of the hedge returns using a t-test based on a boot-strapping procedure. Specifically, we select firm observations that we randomly assign to the ten portfolios. We then calculate the hedge return. We repeat this procedure 1,000 times, thereby generating an empirical distribution that we use to report empirical $p$-values in addition to conventional $t$-statistics and their implied $p$-values.

\section{SAMPLE AND DESCRIPTIVE STATISTICS}

We obtain most of the data for estimation of (4) and (5) for 1976-2006 from the Compustat Primary, Secondary, and Tertiary, Full Coverage, and Research Annual Industrial Files. $D S_{t}$ and $R D S_{t}$ are calculated using Compustat and CRSP data as described in section 3.1. We compute $V C N I_{t}^{a}$ as $V C N I_{t}-r B V E_{t-1}$, where $V C N I_{t}$ includes both $D S_{t}$ and $R D S_{t}$. Following Barth et al. (1999, 2005), Dechow et al. (1999), Bell et al. (2002), and Landsman et al. (2007), we set $r$, the cost-of-equity capital, equal to 12 percent, and we require sample firms to have positive equity book value. ${ }^{13}$ We also require that sample firms have total assets in excess of $\$ 10$ million to avoid the undue influence of small firms. To

\footnotetext{
13 None of our inferences are affected by assuming alternative values for $r$, including firm-specific values based on our multi-factor model.
} 
mitigate the effects of outliers, for each variable within each of the three size categories, we treat as missing observations that are in the extreme top and bottom one percentile. For each sample year, firms are ranked according to end-of-year market value of common equity and assigned into one of three equal sized groups of firms comprising the small, medium, and large firms. We estimate (4) and (5) using unscaled data (Barth and Kallapur 1996). We assess significance of regression coefficients using two-way clustered standard errors, with firm and year clusters (Petersen 2009). ${ }^{14}$ The final sample for estimation of (4) and (5) comprises 37,097 firm-year observations.

We obtain stock return, $R$, from CRSP and $R_{f}$, the one-month Treasury rate, and the Fama-French and momentum factor returns from the Fama-French database (http://www.mba.tuck.dartmouth.edu/pages/faculty/ken.french/data_library). To obtain excess returns per (6), we estimate factor loadings from (7) using monthly return data beginning in 1972. ${ }^{15}$ There are 30,383 potential $D S$ firm-year excess return observations. However, because there are 17,579 observations with zero $D S$, we limit our $D S$ hedge return analysis to the 12,804 non-zero observations. There are $28,346 R D S$ firm-year excess return

\footnotetext{
${ }^{14}$ We also compute significance levels using bootstrapping. Untabulated findings result in no changes in inferences from those based on reported findings for $R D S$. For $D S$, the forecasting and valuation coefficients are still consistent, but with both significantly positive forecasting and valuation coefficients for small and medium firms.

15 Although excess returns can be computed through 2006, our sample stops in 2003. This is because we compute hedge returns for one, two, and three-year horizons, and to facilitate comparison over returns time, we use a common sample for the full three year horizon.
} 
observations.

Table 1, Panel A presents distributional statistics and Panel B presents Pearson and Spearman correlations. Panel A reveals that, on average, the market value of equity exceeds the book value of equity for all size firms and mean abnormal earnings, $V C N I^{a}$, is positive for large firms but negative for medium and small firms. Table 1, Panel B reveals that the explanatory variables in (4) and (5) are correlated with each other, but not so much as to raise collinearity concerns. Although the distributional statistics reported in Panel A reveal the variables are skewed, none of the key inferences are affected when the equations are estimated on a per share basis.

\section{INSERT TABLE 1 ABOUT HERE}

Because typically $P_{t}^{M}>P_{t}^{A}$ and $N_{t}>N_{t-1}$, we expect $R D S$ to be negative. Table 1 , Panel A reveals that $R D S$ turns positive before the $75^{\text {th }}$ percentile. Untabulated statistics reveal that $R D S$ turns positive between the $60^{\text {th }}$ and $70^{\text {th }}$ percentiles for two-thirds of the sample years, and beyond the $70^{\text {th }}$ percentile for the remaining third. Because it is unlikely that equity transactions will give rise to positive $R D S$, this means that at least some of our observations are measured with error. Assuming this error is unsystematic, the implication of this is a reduction in power of our tests, particularly those relating to the hedge returns. Untabulated statistics reveal that mean $R D S$ is economically largest (i.e., most negative) for Pharmaceuticals, Services, Food, and Computers, and that mean $R D S$ is 
economically largest in 1997, 1998, and 2002. To mitigate the impact of particular industries or years overly influencing our results, below we report supplementary findings from hedge return tests that exclude those industries and years with the largest mean $R D S$ values.

\section{RESULTS}

\section{Forecasting Equations}

Table 2, Panel A presents regression summary statistics from estimating equation (4).

We employ separate estimations for small, medium, and large firms and the pooled sample.

Panel A reveals in all cases, the forecasting coefficient for abnormal very comprehensive

income, $\omega_{1}$, is significantly positive. It is also increasing in firm size, which is consistent with greater persistence for larger firms.

\section{INSERT TABLE 2 ABOUT HERE}

The incremental forecasting coefficient for $D S, \omega_{2}$, is significantly different from zero for only the large firms. More importantly, the total $D S$ forecasting coefficient, $\omega_{1}+\omega_{2}$, is insignificantly different from zero for all three groups of firms and for the pooled sample $(t$-statistics $=0.46,0.98,0.59$, and 0.59$) .{ }^{16}$ These findings indicate that $D S$ is forecasting irrelevant for $V C N I^{a}$ for all firms. If investors correctly understand the implications of these persistence findings for valuation, then we should observe valuation irrelevance of $D S$ for all firms, i.e., $D S$ should have a zero total valuation coefficient in the valuation equation.

\footnotetext{
16 Throughout we use a 0.05 significance level under a two-sided alternative when evaluating statistical significance.
} 
The incremental forecasting coefficient for $R D S, \omega_{3}$, is significantly negative in all cases. The total $R D S$ forecasting coefficient, $\omega_{1}+\omega_{3}$, is insignificantly different from zero for all size firms and the pooled sample $(t$-statistics $=1.29,0.84,-0.85$, and -0.81$)$. These findings indicate that $R D S$ is forecasting irrelevant for $V C N I^{a}$ for all firms. As with $D S$, if investors correctly understand the implications of these persistence findings for valuation, then we should observe valuation irrelevance of $R D S$ for all firms.

\section{Valuation Equations}

Table 2, Panel B reveals the valuation coefficient for $V C N I^{a}, \alpha_{1}$, is significantly positive in all cases. It is also increasing in firm size, ranging from 1.05 for small firms to 7.83 for large firms, which is consistent with the pattern of increasing persistence displayed in Table 2, Panel A.

The incremental valuation coefficient for $D S, \alpha_{2}$, is insignificantly different from zero for small and medium firms and significantly negative for large firms. More importantly, its total coefficient, $\alpha_{1}+\alpha_{2}$, is also insignificantly different from zero for all three groups as well as the pooled sample $(t$-statistics $=1.03,1.10,-0.39$, and -0.43$)$. This finding is expected based on the findings about the lack of persistence for $D S$ revealed in Table 2, Panel A.

The incremental valuation coefficient for $R D S, \alpha_{3}$, is significantly negative in all cases. Its total coefficient, $\alpha_{1}+\alpha_{3}$, is also significantly negative for all groups $(t$-statistics $=$ $-5.45,-8.37,-4.76$, and -4.93$)$. Based on the forecasting coefficient findings in Table 2, 
Panel A, we expect to observe $\alpha_{1}+\alpha_{3}$ to be insignificantly different from zero for all size

firms. However, finding that $\alpha_{1}+\alpha_{3}<0$ implies that an incremental dollar of $R D S$

increases market value by less than a dollar. ${ }^{17}$ Thus investors appear to undervalue the $R D S$

component of income, i.e., over-value equity. ${ }^{18}$

\section{Dirty Surplus Hedge Returns}

Table 3 reports buy-and-hold Fama-French risk-adjusted stock returns for firms in the top and bottom three deciles of firms classified according to the (signed) magnitude of $D S$ as a fraction of equity book value at the beginning of the cumulation period. Results are presented separately for small, medium, and large firms, and for the pooled sample. The table presents mean returns for one-, two- and three-year horizons and the median values of $D S / B V E$ for each group, as well as hedge returns and associated t-statistics and empirical $p$-values.

\section{INSERT TABLE 3 ABOUT HERE}

\footnotetext{
17 Note that the market's treatment of $R D S$ as having negative persistence can be restated as implying that the market views the benefits to the firm from a transaction that give rise to $R D S$ as exceeding its $R D S$ costs. For this to occur, the market would have to believe that benefits would flow to the firm in future periods at a level beyond that which could be inferred from the time series properties of residual income. In other words, RDS would play two roles-being both a current period cost and a proxy for an Ohlson-type other information variable. An example of this is the market believing an intangible asset arising from employee stock options is greater than the dilution cost to current shareholders.

18 The findings in Table 2 could be attributable to variables predictive of future earnings and returns that are correlated with $R D S$. Fairfield et al. (2003) identify two such accounting-based variables, short-term accruals and growth in net operating assets. Untabulated findings reveal that inclusion of these variables in (4) and (5) does not affect any inferences we draw from Table 2.
} 
The findings indicate that for medium and large firms, and for the pooled sample,

mean risk-adjusted returns and associated hedge returns for all three horizons are essentially

zero. However, for small firms, the mean risk-adjusted returns are positive and monotonically

increasing over the three-year horizon, suggesting that Fama-French risk adjustments may not

perfectly eliminate the pricing effects of risk. Nonetheless, the small firm hedge returns are

zero, indicating that the mismeasurement of expected return for small firms is unrelated to

assignment of observations to $D S$ portfolios. The small firm hedge returns being zero is

consistent with investors pricing $D S$ correctly.

Taken together, the findings in Tables 2 and 3 suggest little evidence of mispricing of stocks based on the magnitude of $D S$. Alternatively, the findings suggest investors make no adjustments to reflect $D S$ items, but this has no pricing implications, because when earnings items are transitory they should only be impounded into price as a result of being included in the book value of equity.

\section{Really Dirty Surplus Hedge Returns}

Table 4 reports buy-and-hold Fama-French risk-adjusted stock returns for firms in the top and bottom three deciles of firms classified according to the (signed) magnitude of $R D S$ as a fraction of equity book value at the beginning of the cumulation period. Table 4 presents analogous statistics to those presented in Table 3, but are based on $R D S$ rather than $D S$. 
Results are presented separately for small, medium, and large firms, and for the pooled sample.

\section{INSERT TABLE 4 ABOUT HERE}

In contrast to Table 3, the findings in Table 4 generally indicate that risk-adjusted returns differ from zero for all firm groups across all three horizons. In addition, the returns move increasingly away from zero in absolute terms over the investing horizon for almost every portfolio. This is particularly pronounced for small firms, for which the one-, two-, and three-year risk-adjusted returns for the top 30 percent (bottom 30 percent) portfolios are 0.08 , 0.12 , and $0.17(0.03,0.06,0.08)$. Recall that the excess returns for small firms in Table 3 also are positive and almost identical for firms in the bottom and top 30 percent portfolios, which we attribute to the difficulty of measuring expected return for small firms. We can therefore treat the excess returns for small firms reported in Table 3 as a benchmark for the measurement error in expected return. Using this approach, we can deduct the average of the two portfolio returns for each investing horizon to arrive at a better estimate of risk-adjusted returns for the small firms. This results in one-, two-, and three-year risk-adjusted returns for the top 30 percent (bottom 30 percent) portfolios of $0.01,0.02$, and $0.02(-0.06,-0.04$, 
$-0.07)$. Note that these additional risk adjustments for the small firms have no effect on their hedge returns because the same adjustment is made to both the long and short positions. ${ }^{19}$

Turning to the hedge returns, Table 4 reveals that they are significantly positive in all three firm size groups and for the pooled sample. Table 4 also reveals that the hedge returns are increasing over time. For example, for small firms, the one-, two-, and three-year hedge returns are $0.06,0.07$, and 0.09 . It is possible that the increasing hedge returns over time could be attributable to an unmodeled risk factor. ${ }^{20,21}$

\section{Additional RDS Hedge Return Tests}

In this section, we consider several additional tests to examine the sensitivity of the $R D S$ hedge returns to previously documented pricing anomalies and risk factors, and to alternative procedures for computing those returns. We also attempt to determine the extent to which different source components of $R D S$ account for our hedge return results.

\footnotetext{
19 A similar adjustment to excess returns for medium and large firms could be made. However, Table 3 indicates that excess returns for medium and large firms are bounded between -0.01 and 0.02 , which suggests that measurement error in expected returns is relatively immaterial for these groups of firms.

${ }^{20}$ One possible candidate is firm size, as Table 4 indicates that firms in bottom $30 \%$ RDS portfolios are roughly twice as large as those in the top $30 \%$. To assess the importance of firm size on hedge returns, we regressed excess return on firm size and an indicator variable for whether a firm-year observation is in the top $30 \% \operatorname{RDS}$ portfolio. Untabulated findings indicate that the indicator variable coefficient is significantly positive in all cases and over all horizons, and the coefficient on size is insignificant in all specifications.

${ }^{21}$ In addition, it is possible that significant hedge returns are induced by our implementation of risk-adjusting returns. Untabulated hedge returns computed without explicit adjustment for risk yield inferences consistent with those based on the tabulated findings.
} 
First, we investigate whether the persistence of the $R D S$ hedge returns could reflect the effects of pricing anomalies documented in prior research. We consider each anomaly, in turn, by first placing observations into one of ten portfolios based on the magnitude of each anomaly factor. Then, within each portfolio, we rank observations according to the magnitude of $R D S$ as a fraction of $B V E$, assigning each observation within each anomaly portfolio to one of ten $R D S$ portfolios. This double-sorting process helps to ensure that our findings are not the result of the particular anomaly used in the initial sort.

The pricing anomalies we consider are: the short-term accruals anomaly (Sloan 1996; Xie 2001); the growth in long-term asset accrual anomaly (Fairfield et al. 2003); the long-term pricing reversal anomaly (Daniel and Titman 2006; Fama and French 2008a), and the share repurchase and issuance anomaly (Ikenberry et al. 1995;Daniel and Titman 2006; Mitchell and Stafford 2000; Fama and French 2008a). The share repurchase and issuance anomaly is potentially most closely related to the $R D S$ pricing anomaly we document because the latter can only arise from equity transactions. Untabulated findings reveal that $R D S$ hedge returns remain significantly positive after controlling for the potential confounding effects of each of the four anomalies. Thus, mispricing associated with previously documented anomalies appears not to account for our finding investor mispricing of $R D S$.

Second, we consider an alternative to our buy-and-hold procedure for computing $R D S$ hedge returns. Following Marshruwala et al. (2006), we estimate hedge returns using a 
monthly calendar-time portfolio approach (Fama and French 1993). Under this approach, hedge returns are calculated based on Jensen's alphas from monthly time-series regressions of hedge portfolio excess returns on Fama-French and momentum factor returns. For each sample year, we assign firms into decile portfolios based on $R D S$ as a fraction of equity book value and compute the mean monthly portfolio return for firms in the top and bottom three deciles. We then estimate the following monthly time-series regression for both the high and low RDS portfolios:

$$
R_{p, t}-R_{f, t}=\alpha_{p}+\beta_{p}\left(R_{M, t}-R_{f, t}\right)+s_{p} S M B_{t}+h_{p} H M L_{t}+m_{p} M O M_{t}+\varepsilon_{p, t}
$$

The resulting Jensen's alpha, $\alpha_{p}$, measures the mean monthly return for portfolio $p$ not attributable to the Fama-French and momentum factor returns. We predict that $\alpha_{p}$ for the high $R D S$ portfolio is larger than that for the low $R D S$ portfolio. We formally test this by estimating (8) for a hedge portfolio, which is constructed as the difference in mean monthly excess returns for the high $R D S$ and low $R D S$ portfolios, ${ }^{22}$ and then testing whether the resulting Jensen's alpha is significantly positive.

Consistent with our predictions, untabulated findings indicate that Jensen's alpha for the high $R D S$ portfolio is larger than that for low portfolio for all three firm size groups: 0.005 vs. 0.003 (small firms); 0.001 vs. 0.000 (medium firms); 0.001 vs. 0.000 (large firms). For the pooled sample, the high and low portfolio Jensen's alpha are 0.002 and 0.000 ,

\footnotetext{
22 The independent variables (risk factors) are the same for each portfolio and are therefore included in the hedge portfolio without adjustment.
} 
respectively. The Jensen's alpha of the hedge portfolio is statistically significant for only the small firms and the pooled sample, $0.003(t$-statistic $=2.25 ; p$-value $=0.03)$ and 0.002 (t-statistic $=2.27 ; p$-value $=0.02)$, which in annual terms indicate excess returns to the $R D S$-based hedging strategy of 3.7 percent and 2.4 percent respectively. These findings contrast with those from the buy-and-hold hedge returns in Table 4, which indicate hedge returns are positive for all three firm size groups. Ascertaining which approach yields the more reliable results is not straightforward. For example, the buy-and-hold approach has the advantage of updating the individual stock's expected return on a monthly basis using out-of-sample estimation, and the alpha approach assumes that factor betas are constant during the test period. ${ }^{23}$

Third, we attempt to determine the extent to which different source components of $R D S$ account for our hedge return results. Findings from the forecasting and valuation tests are consistent with, in the aggregate, $R D S$ components of very comprehensive net income being transitory, but investors failing to understand this and over-valuing equity. Ideally, we would like to identify separate components of $R D S$, determine their persistence, and then ascertain which components investors appear to fail to price correctly. Because we face the same data limitations as investors, we can only do this indirectly by sequentially excluding and including firm-years in which $R D S$ is more likely to be attributable to one particular type

${ }^{23}$ For a discussion of the strengths and weaknesses of the various approaches, see Fama and French (2008b). 
of transaction. First, to focus on the potential pricing effects of pooling-of-interests

transactions, we recomputed hedge returns (a) excluding firm-years with corporate mergers or acquisitions, and (b) using only firm years with corporate mergers. ${ }^{24}$ Second, to focus on the potential pricing effects of employee stock options, we recomputed hedge returns using (a) only observations beginning in 1995, and (b) only observations before 1995. Because SFAS 123 required disclosure of weighted average exercise price for employee stock options after 1995, hedge returns might be expected to fall or even disappear in this latter period. Third, to focus more generally on the pricing effects of dilutive transactions, including warrants, convertible instruments, as well as stock options, we recomputed hedge returns for portfolios sorting firm-year observations on the difference between basic and diluted earnings per share as a fraction of equity book value. Finally, because $R D S$ is concentrated in particular industries and years, as noted in Section IV, we sequentially calculated hedge returns excluding the six industries and the five years with the most negative $R D S$. Untabulated findings from each of these additional analyses reveal that hedge returns remain significant in all cases. These findings are consistent with our tests lacking power to trace the precise sources of $R D S$. They are also consistent with $R D S$ being correlated with an unmodeled risk factor.

\footnotetext{
24 Ideally, we would compute hedge returns for subsamples excluding and including only those firm-years with mergers accounted for under pooling-of-interests. However, because such identifying information is only available to us using the Securities Data Corporation beginning in the middle of our sample period, we elected to cast the net wider to take account of mergers and acquisitions during our sample period.
} 


\section{CONCLUSIONS}

The question we address in this study is whether firms' share prices correctly reflect

two accounting measures, dirty surplus and really dirty surplus. We find that both dirty

surplus and really dirty surplus are forecasting irrelevant for abnormal very comprehensive

income for all firm size groups. Taking these results at face value (i.e., assuming that the

forecasting and valuation equations correctly capture the time series properties of these

variables), if investors correctly understand the implications of these persistence findings for

valuation, then each kind of dirty surplus should be valuation irrelevant for all firms. This

prediction is borne out in the case of dirty surplus. In contrast, the findings indicate that

investors appear to undervalue really dirty surplus, which is consistent with the premise that

investors are unable to assess the economic implications of really dirty surplus transactions.

However, the possibility remains that the mismatch of the really dirty surplus forecasting and

valuation coefficients is the result of model misspecification rather than mispricing.

Our buy-and-hold hedge return results support the findings from the tests linking the

forecasting and valuation equations. Hedge returns are insignificantly different from zero

when based upon dirty surplus, regardless of firm size and investing horizon. In contrast,

buy-and-hold hedge returns based on really dirty surplus are significantly positive for three

firm size groups as well as for the pooled sample. Findings from additional tests reveal that

inferences relating to hedge returns are insensitive to an alternative procedure to measuring 
hedge returns, to including controls for four previously identified mispricing anomalies, and to sampling procedures designed to focus on sources of really dirty surplus.

Taken together, the findings are consistent with investors failing to understand the lack of persistence of really dirty surplus, and therefore apparently overvaluing firms that have large negative really dirty surplus. However, because we are unable to trace the sources of really dirty surplus to particular types of equity transactions, we cannot determine the extent to which potential mispricing arises from each type of transaction. However, even if we could trace the sources of really dirty surplus, any resulting hedge returns might still be attributable to an unmodeled risk factor. 


\section{REFERENCES}

Ang, A., and J. Liu. 2004. How to discount cash flows with time-varying expected returns. Journal of Finance 59 (6): 2745-2783.

Barth, M.E., and S. Kallapur. 1996. Effects of cross-sectional scale differences on regression results in empirical accounting research. Contemporary Accounting Research 13 (2): $527-567$.

Barth, M.E., W.H. Beaver, J.M. Hand, and W.R. Landsman. 1999. Accruals, cash flows, and equity values. Review of Accounting Studies 4 (3-4): 205-229.

Barth, M.E., W.H. Beaver, J.M. Hand, and W.R. Landsman. 2005. Accruals, accounting-based valuation models, and the prediction of equity values. Journal of Accounting, Auditing, and Finance 20 (4): 311-345.

Barth, M.E., Y. Konchitchki, and W.R. Landsman. 2008. Cost of capital and financial statements transparency. Working paper, Stanford University.

Bell, T., W. R. Landsman, B. Miller, and S. Yeh. 2002. The valuation implications of employee stock option accounting for profitable computer software firms. The Accounting Review 77 (4): 971-996.

Bernard, V., and J. Thomas. 1989. Post-earnings-announcement drift: Delayed price response or risk premium? Journal of Accounting Research 27 (supplement): 1-48.

Bernard, V., and J. Thomas. 1990. Evidence that stock prices do not fully reflect the 
implications of current earnings for future earnings. Journal of Accounting and

Economics 13 (4): 305-340.

Biddle, G., and J. Choi. 2006. Is comprehensive income useful? Journal of Contemporary Accounting and Economics 2 (1): 1-32.

Bradshaw, M., and R.G. Sloan. 2002. GAAP versus the Street: An empirical assessment of two alternative definitions of earnings. Journal of Accounting Research 40 (1): 41-66.

Brown, L., and K. Sivakumar. 2003. Comparing the value relevance of two operating income measures. Review of Accounting Studies 8 (4): 561-572.

Burgstahler, D., J. Jiambalvo, and T. Shevlin. 2002. Do stock prices fully reflect the implications of special items for future earnings? Journal of Accounting Research 40 (3): 585-612.

Carhart, M. 1997. On persistence in mutual fund performance. Journal of Finance 52 (1): 57-82.

Chambers, D., T.J. Linsmeier, C. Shakespeare, and T. Sougiannis. 2007. An evaluation of SFAS No. 130 comprehensive income disclosures. Review of Accounting Studies 12 (4): 557-593.

Christensen, P., and G. A. Feltham. 2003. Economics of Accounting. Boston, MA: Kluwer Academic Publishers.

Core, J., W. Guay, and S.P. Kothari. 2002. The economic dilution of employee stock options: 
Diluted EPS for valuation and financial reporting. The Accounting Review 77 (3):

$627-652$.

Daniel, K., and S. Titman. 2006. Market reactions to tangible and intangible information.

Journal of Finance 61 (4): 1605-1643.

Dechow, P.M., Hutton, A.P., and R.G. Sloan. 1999. An empirical assessment of the residual income valuation model. Journal of Accounting and Economics 26 (1-3): 1-34.

Dhaliwal, D., K.R. Subramanyam, and R. Trezevant. 1999. Is comprehensive income superior to net income as a measure of firm performance? Journal of Accounting and Economics 26(1-3): 43-67.

Doyle, J.T., R.J. Lundholm, and M.T. Soliman. 2003. The predictive value of expenses excluded from 'pro forma' earnings. Review of Accounting Studies 8 (2-3): 145-174.

Fairfield, P.M., J.S. Whisenant, and T.L. Yohn. 2003. Accrued earnings and growth: Implications for future profitability and market mispricing. The Accounting Review 78 (1): 353-371.

Fama, E.F., and K.R. French. 1993. Common-size risk factors in the returns on stocks and bonds. Journal of Financial Economics 33 (1): 3-56.

Fama, E.F., and K.R. French. 2008a. Average returns, B/M, and share issues. Journal of Finance 63 (6): 2971-2995.

Fama, E.F., and K.R. French. 2008b. Dissecting anomalies. Journal of Finance 63 (4): 
1653-1678.

Feltham, G. 1996. Valuation, clean surplus accounting, and anticipated equity transactions.

Working paper, University of British Columbia.

Feltham, G., and J. Ohlson. 1995. Valuation and clean surplus accounting for operating and financial activities. Contemporary Accounting Research 11 (2): 689-731.

Ibbotson and Associates. 2005. Cost of Capital 2005 Yearbook. Chicago, Illinois: Ibbotson and Associates.

Ikenberry, D., J. Lakonishok, and T. Vermaelen. 1995. Market underreaction to open market share repurchases. Journal of Financial Economics 39 (2-3): 181-208

Jegadeesh, N., and S. Titman 1993. Returns to buying winners and selling losers:

Implications for stock market efficiency. Journal of Finance 48 (1): 65-91.

Landsman, W.R., B.L. Miller, and S.Yeh. 2007. Implications of components of income excluded from pro forma earnings for future profitability and equity valuation. Journal of Business Finance and Accounting 34 (3-4): 650-675.

Landsman, W.R., K. Peasnell, P. Pope, and S. Yeh. 2006. Which approach to accounting for employee stock options best reflects market pricing? Review of Accounting Studies 11 (2-3): 203-245.

Marshruwala, C., S. Rajgopal, and T. Shevlin. 2006. Why is the accrual anomaly not arbitraged away? The role of idiosyncratic risk and transactions costs. Journal of Accounting and Economics 42 (1-2): 3-33. 
Massa, M., U. Peyer, and Z. Tong. 2005. Limits of arbitrage and corporate financial policy. Working paper, INSEAD.

Mitchell, M.L., and E. Stafford. 2000. Managerial decisions and long-term stock price performance. Journal of Business 63 (3): 287-329.

O’Hanlon, J., and P. Pope. 1999. The value-relevance of U.K. dirty surplus accounting flows. British Accounting Review 31 (4): 459-482.

Ohlson, J.A. 1995. Earnings, equity book values, and dividends in equity valuation. Contemporary Accounting Research 11 (2): 661-687.

Ohlson, J.A. 1999. On transitory earnings. Review of Accounting Studies 3 (304): 145-162.

Petersen, M.A. 2009. Estimating standard errors in finance panel datasets: Comparing approaches. Review of Financial Studies 22 (1): 435-480.

Sloan, R. 1996. Do stock prices fully reflect information in accruals and cash flows about future earnings? The Accounting Review 71 (3): 289-316.

Xie, H. 2001. The mispricing of abnormal accruals. The Accounting Review 76 (3): 357-373. 
TABLE 1 Descriptive Statistics for Equity Market Value, Equity Book Value, Abnormal Earnings, Dirty Surplus, Really Dirty Surplus for a Sample of 37,097 Firm-Year Observations, 1976-2006

\section{Panel A: Distributional statistics (in \$ million)}

\begin{tabular}{lrrrrr} 
Variable $^{\mathrm{a}}$ & Mean & $25^{\text {th }} \%$ & Median & $75^{\text {th }} \%$ & Std. Dev. \\
\cline { 2 - 6 }$M V E$ & $2,216.57$ & 89.98 & 388.66 & $1,537.13$ & $6,282.58$ \\
$B V E$ & 894.42 & 65.67 & 213.53 & 745.84 & $2,151.25$ \\
$V C N I$ & 102.05 & 2.01 & 15.50 & 73.56 & 377.09 \\
$V C N I^{a}$ & 4.43 & -13.30 & -0.27 & 12.96 & 262.01 \\
$D S$ & 0.68 & 0.00 & 0.00 & 0.00 & 49.43 \\
$R D S$ & -18.90 & -6.27 & -0.42 & 0.02 & 150.51
\end{tabular}

Panel A.1 : Distributional statistics for small Firms (in \$ million)

\begin{tabular}{lrrrrr} 
Variable $^{\mathrm{a}}$ & Mean & $25^{\text {th }} \%$ & Median & $75^{\text {th }} \%$ & Std. Dev. \\
\cline { 2 - 6 }$M V E$ & 85.88 & 24.22 & 50.64 & 99.54 & 102.40 \\
$B V E$ & 64.65 & 20.96 & 40.99 & 81.83 & 66.82 \\
$V C N I$ & 2.37 & -0.18 & 2.46 & 6.51 & 11.83 \\
$V C N I^{a}$ & -5.06 & -6.79 & -1.48 & 0.78 & 13.17 \\
$D S$ & 0.04 & 0.00 & 0.00 & 0.00 & 1.23 \\
$R D S$ & -0.73 & -0.52 & -0.03 & 0.01 & 3.76
\end{tabular}

Panel A.2: Distributional statistics for medium Firms (in \$ million) ${ }^{\text {b }}$

\begin{tabular}{lrrrrr} 
Variable $^{\mathrm{a}}$ & Mean & $25^{\text {th }} \%$ & Median & $75^{\text {th }} \%$ & Std. Dev. \\
\cline { 2 - 6 }$M V E$ & 531.34 & 189.03 & 369.80 & 700.67 & 487.35 \\
$B V E$ & 283.47 & 112.81 & 200.98 & 366.31 & 249.43 \\
$V C N I$ & 22.95 & 7.71 & 18.52 & 37.65 & 43.79 \\
$V C N I^{a}$ & -7.95 & -14.94 & 0.44 & 9.11 & 44.01 \\
$D S$ & 0.27 & 0.00 & 0.00 & 0.00 & 6.62 \\
$R D S$ & -4.61 & -4.94 & -0.67 & 0.02 & 18.51
\end{tabular}

(Continued on next page) 
(Table 1: continued from last page)

Panel A.3 : Distributional statistics for large Firms (in \$ million) ${ }^{\text {b }}$

\begin{tabular}{lrrrrr} 
Variable $^{\mathrm{a}}$ & Mean & $25^{\text {th }} \%$ & Median & $75^{\text {th }} \%$ & Std. Dev. \\
\cline { 2 - 6 }$M V E$ & $5,914.80$ & $1,240.97$ & $2,685.64$ & $6,020.24$ & $9,741.45$ \\
$B V E$ & $2,290.81$ & 602.20 & $1,167.00$ & $2,477.00$ & $3,248.53$ \\
$V C N I$ & 275.33 & 46.54 & 123.25 & 318.75 & 608.33 \\
$V C N I^{a}$ & 25.62 & -52.27 & 18.65 & 97.62 & 446.07 \\
$D S$ & 1.70 & -2.05 & 0.00 & 1.34 & 84.46 \\
$R D S$ & -50.37 & -36.63 & -5.32 & 0.15 & 254.37
\end{tabular}

Panel B: Correlations, with Pearson (Spearman) correlations above (below) the diagonal

\begin{tabular}{lrrrrrr} 
Variable $^{\mathrm{a}}$ & $M V E$ & $B V E$ & $V C N I$ & $V C N I^{a}$ & $D S$ & $R D S$ \\
\cline { 2 - 7 }$M V E$ & 1.000 & 0.802 & 0.733 & 0.343 & 0.044 & -0.251 \\
$B V E$ & 0.942 & 1.000 & 0.761 & 0.206 & 0.059 & -0.202 \\
$V C N I$ & 0.675 & 0.672 & 1.000 & 0.784 & 0.108 & 0.167 \\
$V C N I^{a}$ & 0.186 & 0.105 & 0.628 & 1.000 & 0.118 & 0.431 \\
$D S$ & 0.005 & 0.007 & 0.062 & 0.106 & 1.000 & -0.149 \\
$R D S$ & -0.340 & -0.287 & -0.057 & 0.125 & -0.055 & 1.000
\end{tabular}

(Continued on next page) 


\footnotetext{
${ }^{\mathrm{a}}$ Variable definitions ( in $\$$ million)

$M V E \quad=$ market value of common shares outstanding as of fiscal year-end (Compustat \#24 * \#25).

$B V E=$ book value of common equity as of fiscal year-end (Compustat \#60 + \#227 - \#242).

$V C N I=$ very comprehensive earnings (Compustat $\# 172-\# 19+D S+R D S)$.

$V C N I^{a}=$ abnormal comprehensive earnings, defined as very comprehensive earnings $(V C N I)$ minus $0.12 * B V E$ (lagged one year).

$D S \quad=$ dirty surplus, measured as the sum of (1) change in the balance of unrealized gains or losses on marketable securities (change in Compustat \# 238), (2) change in the cumulative foreign exchange adjustment (change in Compustat \# 230), and (3) 0.65 times change in additional pension liability in excess of unrecognized prior service costs (change in Min (Compustat \#297 - \# 298, 0)).

RDS = really dirty surplus, measured as the change in the book value of common equity (Compustat \#60 + \#227 - \#242), less DS, less net income (Compustat \#172 - \#19), plus dividends (Compustat \#21), less share price at middle of fiscal year times change in common shares outstanding (Compustat \# 25, adjusted for stock dividends and splits).

${ }^{\mathrm{b}}$ Firms are ranked for each sample year according to firm size, i.e., equity market value, and assigned into one of three equal-sized groups of firms comprising the small, medium, and large firms.
} 
Table 2 Regressions of Abnormal Earnings and Equity Market Value, with Dirty Surplus and Really Dirty Surplus Included as Separate Regressors, for a Sample of 37,097 Firm-Year Observations, 1976-2006 ${ }^{\text {a }}$

Panel A: Summary statistics from regression of abnormal earnings on lagged abnormal earnings, dirty surplus, really dirty surplus, and equity book value

$$
V C N I_{i t+1}^{a}=\omega_{0}+\omega_{1} V C N I_{i t}^{a}+\omega_{2} D S_{i t}+\omega_{3} R D S_{i t}+\omega_{4} B V E_{i t}+\varepsilon_{i t+1}
$$

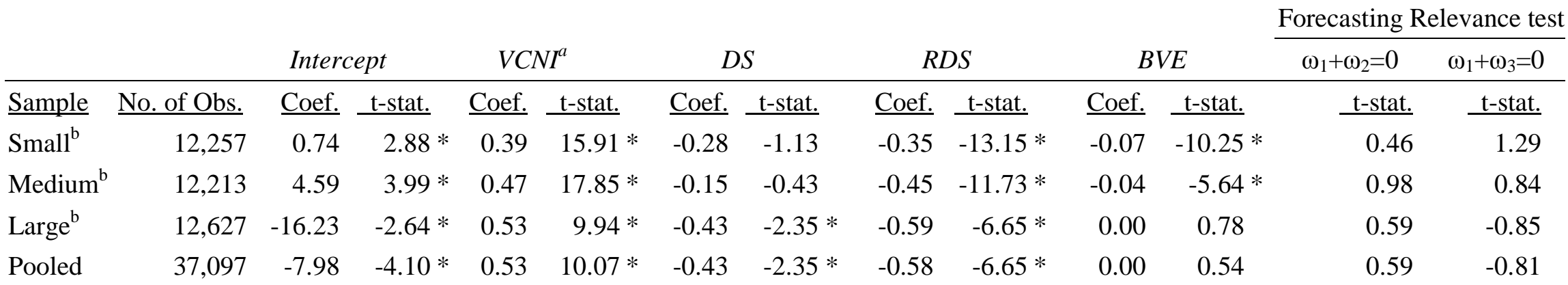

(Continued on next page) 
(Table 2: continued from last page)

Panel B: Summary statistics from regression of market value of equity on abnormal earnings, dirty surplus, really dirty surplus, and equity book value

$$
M V E_{i t}=\alpha_{0}+\alpha_{1} V C N I_{i t}^{a}+\alpha_{2} D S_{i t}+\alpha_{3} R D S_{i t}+\alpha_{4} B V E_{i t}+u_{i t+1}
$$

\begin{tabular}{|c|c|c|c|c|c|c|c|c|c|c|c|c|c|}
\hline \multirow[b]{3}{*}{ Sample } & \multirow[b]{3}{*}{ No. of Obs. } & \multirow{2}{*}{\multicolumn{2}{|c|}{ Intercept }} & \multirow{2}{*}{\multicolumn{2}{|c|}{$V C N I^{a}$}} & \multirow{2}{*}{\multicolumn{2}{|c|}{$D S$}} & \multirow{2}{*}{\multicolumn{2}{|c|}{$R D S$}} & & & \multicolumn{2}{|c|}{ Valuation Relevance test } \\
\hline & & & & & & & & & & \multicolumn{2}{|c|}{$B V E$} & $\alpha_{1}+\alpha_{2}=0$ & $\alpha_{1}+\alpha_{3}=0$ \\
\hline & & Coef. & t-stat. & Coef. & t-stat. & Coef. & t-stat. & Coef. & t-stat. & Coef. & t-stat. & t-stat. & t-stat. \\
\hline Small $^{\mathrm{b}}$ & 12,257 & 8.85 & $2.17 *$ & 1.05 & $8.66 *$ & 1.21 & 0.55 & -3.56 & $-6.81 *$ & 1.23 & $12.47 *$ & 1.03 & $-5.45 *$ \\
\hline Medium $^{\mathrm{b}}$ & 12,213 & 101.80 & $3.39 *$ & 2.72 & $8.13 *$ & -0.21 & -0.09 & -5.09 & $-9.53 *$ & 1.51 & $13.56 *$ & 1.10 & $-8.37 *$ \\
\hline Large $^{b}$ & 12,627 & 766.66 & $4.11 *$ & 7.83 & $10.37 *$ & -9.30 & $-2.33 *$ & -10.88 & $-9.50 *$ & 1.93 & $15.87 *$ & -0.39 & $-4.76 *$ \\
\hline Pooled & 37,097 & 187.08 & $3.27 *$ & 7.76 & $10.39 *$ & -9.37 & $-2.34 *$ & -10.96 & $-9.60 *$ & 2.01 & $16.94 *$ & -0.43 & $-4.93 *$ \\
\hline
\end{tabular}

${ }^{\mathrm{a}}$ See Table 1 for definitions of all variables.

${ }^{\mathrm{b}}$ Firms are ranked for each sample year according to firm size, i.e., equity market value, and assigned into one of three equal-sized groups of firms comprising the small, medium, and large firms.

$*(\wedge)$ indicates coefficient is significantly different from zero at less than the $0.05(0.10)$ level. 
Table 3 Mean Fama-French Risk-adjusted Stock Returns in Top and Bottom Three Deciles of Non-zero Dirty Surplus Deflated by Book Value of Owner Equity for a Sample of 12,804 Firm-Year Observations, 1976-2003 a,b

$\underline{\text { Small Firms }^{\mathrm{c}}}$

Portfolio $^{\mathrm{c}}$

Bottom $30 \%$

Top $30 \%$

Hedge Return $^{\mathrm{d}}$

t-stat.

Empirical p-value

\begin{tabular}{rrrrrr} 
no. of obs. & $\underline{M V E}$ & $\underline{D S / B V E}$ & $\underline{1 \text { year }}$ & $\underline{2 \text { Year }}$ & $\underline{3 \text { Year }}$ \\
\hline 1,314 & 162.30 & -0.022 & 0.08 & 0.11 & 0.16 \\
1,303 & 146.09 & 0.016 & 0.07 & 0.10 & 0.15 \\
& & & -0.01 & 0.00 & 0.00 \\
& & & -0.51 & -0.13 & -0.07 \\
& & & 0.72 & 0.56 & 0.54
\end{tabular}

$\underline{\text { Medium Firms }}^{\mathrm{c}}$

Portfolio $^{\text {c }}$
Bottom $30 \%$
Top $30 \%$
Hedge Return
t-stat.
Empirical p-value

\begin{tabular}{rrrrrr}
$\underline{\text { no. of obs. }}$ & $\underline{M V E}$ & $\underline{D S / B V E}$ & $\underline{1 \text { year }}$ & $\underline{2 \text { Year }}$ & $\frac{3 \text { Year }}{1,279}$ \\
\hline $1,075.51$ & -0.021 & -0.01 & 0.00 & 0.01 \\
1,272 & 934.83 & 0.016 & 0.02 & 0.01 & 0.00 \\
& & & 0.03 & 0.00 & -0.02 \\
& & & $1.71 \wedge$ & 0.20 & -0.62 \\
& & & 0.03 & 0.39 & 0.73
\end{tabular}

Large Firms $^{\mathrm{c}}$

\begin{tabular}{|c|c|c|c|c|c|c|}
\hline$\underline{\text { Portfolio }}^{c}$ & no. of obs. & $\underline{M V E}$ & $\underline{D S / B V E}$ & 1 year & 2 Year & 3 Year \\
\hline Bottom $30 \%$ & 1,260 & $14,073.49$ & -0.023 & 0.00 & 0.00 & 0.00 \\
\hline Top $30 \%$ & 1,254 & $12,525.09$ & 0.016 & 0.01 & -0.01 & -0.01 \\
\hline Hedge Return $^{\mathrm{d}}$ & & & & 0.00 & -0.01 & -0.01 \\
\hline t-stat. & & & & 0.34 & -0.46 & -0.55 \\
\hline Empirical p-value & & & & 0.36 & 0.71 & 0.73 \\
\hline \multicolumn{7}{|l|}{ Pooled Sample } \\
\hline$\underline{\text { Portfolio }}^{c}$ & no. of obs. & $\underline{M V E}$ & $\underline{D S / B V E}$ & 1 year & 2 Year & 3 Year \\
\hline Bottom $30 \%$ & 3,853 & $5,014.65$ & -0.022 & 0.03 & 0.04 & 0.06 \\
\hline Top 30\% & 3,829 & $4,462.24$ & 0.016 & 0.03 & 0.03 & 0.05 \\
\hline Hedge Return $^{\mathrm{d}}$ & & & & 0.01 & -0.00 & -0.01 \\
\hline t-stat. & & & & 0.55 & -0.19 & -0.49 \\
\hline Empirical p-value $\mathrm{e}^{\mathrm{e}}$ & & & & 0.33 & 0.58 & 0.67 \\
\hline
\end{tabular}

(Continued on next page) 
(Table 3: continued from last page)

${ }^{\text {a }}$ See Table 1 for definitions of all variables

${ }^{\mathrm{b}}$ Fama-French risk-adjusted return is a firm's actual return in excess of the risk-free rate less the firm's predicted return based on the Fama-French factor and momentum factor mimicking portfolios, i.e., excess market return, size, book-to-market, and momentum factor.

${ }^{\text {c }}$ Firm's size designation and $D S$ portfolio ranking are assigned in the following procedure: for each sample year, firms are ranked according to $D S$ as a fraction of end of year equity book value, $B V E$ and assigned into ten equal sized portfolios whereby the first (tenth) portfolio contains those observations with the smallest (largest) fraction of $D S$; within each of the ten $D S$ portfolios, firms are ranked according to firm size, i.e., equity market value, and are assigned into to one of three equal sized groups of firms comprising the small, medium, and large firms.

${ }^{d}$ The hedge return is computed by deducting the mean risk adjusted return on the bottom three deciles portfolio from that on the top three deciles portfolio. The strategy implementation begins three months subsequent to the firm's fiscal year end.

${ }^{\mathrm{e}}$ The proportion of the hedge returns from 1,000 simulations exceeds the observed $D S$-based hedge return. In a simulation, each firm is assigned a random number as the substitute for $D S$, and accordingly the portfolio ranking and size designation following the procedure in footnote $\mathrm{c}$.

$*(\wedge)$ indicates hedge return is significantly different from zero at less than the $0.05(0.10)$ level. 
Table 4 Mean Fama-French Risk-adjusted Stock Returns in Top and Bottom Three Deciles of Really Dirty Surplus Deflated by Book Value of Owner Equity for a Sample of 28,346 Firm-Year Observations, 1976-2003

$\underline{\text { Small Firms Portfolio }}^{\mathrm{c}}$

$\begin{array}{lcccccc} & \text { no. of obs. } & \underline{M V E} & \underline{R D S / B V E} & \underline{1 \text { year }} & \underline{2 \text { Year }} & \underline{3 \text { Year }} \\ \text { Bottom 30\% } & 2,870 & 114.23 & -0.046 & 0.03 & 0.06 & 0.08 \\ \text { Top 30\% } & 2,860 & 54.91 & 0.004 & 0.08 & 0.12 & 0.17 \\ \text { Hedge Return }^{\mathrm{d}} & & & & 0.06 & 0.07 & 0.09 \\ \text { t-stat. } & & & & 3.61 * & 2.61 * & 2.81 * \\ \text { Empirical p-value }^{\mathrm{e}} & & & & <0.01 & 0.01 & <0.01\end{array}$

$\underline{\text { Medium Firms Portfolio }^{c}}$

$\begin{array}{lcccccr} & \text { no. of obs. } & \underline{M V E} & \frac{R D S / B V E}{2} & \underline{1 \text { year }} & \underline{2 \text { Year }} & \underline{3 \text { Year }} \\ \text { Bottom 30\% } & 2,834 & 670.28 & -0.046 & -0.02 & -0.05 & -0.07 \\ \text { Top 30\% } & 2,824 & 351.69 & 0.004 & 0.01 & 0.01 & 0.00 \\ \text { Hedge Return }^{\mathrm{d}} & & & & 0.03 & 0.06 & 0.07 \\ \text { t-stat. } & & & 2.71 * & 3.92 * & 3.94 * \\ \text { Empirical p-value }^{\mathrm{e}} & & & & <0.01 & <0.01 & <0.01\end{array}$

$\underline{\text { Large Firms Portfolio }^{c}}$

\begin{tabular}{|c|c|c|c|c|c|c|}
\hline & no. of obs. & $\underline{M V E}$ & $\underline{R D S / B V E}$ & 1 year & 2 Year & 3 Year \\
\hline Bottom $30 \%$ & 2,812 & $\begin{array}{c}10,156.3 \\
5\end{array}$ & -0.047 & -0.02 & -0.04 & -0.06 \\
\hline Top $30 \%$ & 2,805 & $5,625.89$ & 0.004 & 0.01 & 0.02 & 0.02 \\
\hline Hedge Return $^{\mathrm{d}}$ & & & & 0.04 & 0.06 & 0.08 \\
\hline t-stat. & & & & $4.25 *$ & $5.39 *$ & $5.83 *$ \\
\hline Empirical p-value & & & & $<0.01$ & $<0.01$ & $<0.01$ \\
\hline \multicolumn{7}{|c|}{$\underline{\text { Pooled Sample Portfolio }}^{c}$} \\
\hline & no. of obs. & $\underline{M V E}$ & $\underline{R D S / B E}$ & 1 year & 2 Year & 3 Year \\
\hline Bottom $30 \%$ & 8,516 & $3,615.20$ & -0.046 & -0.01 & -0.01 & -0.02 \\
\hline Top 30\% & 8,489 & $1,994.44$ & 0.004 & 0.04 & 0.05 & 0.07 \\
\hline Hedge Return $^{\mathrm{d}}$ & & & & 0.04 & 0.06 & 0.08 \\
\hline t-stat. & & & & $5.84 *$ & $5.81 *$ & $6.00 *$ \\
\hline Empirical p-value & & & & $<0.01$ & $<0.01$ & $<0.01$ \\
\hline
\end{tabular}

(Continued on next page) 
(Table 4: continued from last page)

${ }^{\text {a }}$ See Table 1 for definitions of all variables

${ }^{\mathrm{b}}$ Fama-French risk-adjusted return is a firm's actual return in excess of the risk-free rate less the firm's predicted return based on the Fama-French factor and momentum factor mimicking portfolios, i.e., excess market return, size, book-to-market, and momentum factor.

' Firm's size designation and $R D S$ portfolio ranking are assigned in the following procedure: for each sample year, firms are ranked according to $R D S$ as a fraction of end of year equity book value, $B V E$, and assigned into ten equal sized portfolios whereby the first (tenth) portfolio contains those observations with the smallest (largest) fraction of $R D S$; within each of the ten $R D S$ portfolios, firms are ranked according to firm size, i.e., equity market value, and are assigned into to one of three equal sized groups of firms comprising the small, medium, and large firms.

${ }^{d}$ The hedge return is computed by deducting the mean risk adjusted return on the bottom three deciles portfolio from that on the top three deciles portfolio. The strategy implementation begins three months subsequent to the firm's fiscal year end.

${ }^{\mathrm{e}}$ The proportion of the hedge returns from 1,000 simulations exceeds the observed $R D S$-based hedge return. In a simulation, each firm is assigned a random number as the substitute for $R D S$, and accordingly the portfolio ranking and size designation following the procedure in footnote $\mathrm{c}$.

$*(\wedge)$ indicates hedge return is significantly different from zero at less than the $0.05(0.10)$ level. 